\title{
Development of a Lesion-Mimic Phenotype in a Transgenic Wheat Line Overexpressing Genes for Pathogenesis-Related (PR) Proteins Is Dependent on Salicylic Acid Concentration
}

\author{
Ajith Anand, ${ }^{1}$ Eric A. Schmelz, ${ }^{2}$ and Subbaratnam Muthukrishnan ${ }^{1}$ \\ ${ }^{1}$ Department of Biochemistry, Kansas State University, Manhattan, KS 66506, U.S.A.; ${ }^{2}$ USDA-ARS-CMAVE Chemistry, \\ 1700 SW 23rd Drive, Gainesville FL 32608, U.S.A.
}

Submitted 17 March 2003. Accepted 10 June 2003.

In the course of coexpressing genes for pathogenesisrelated (PR) proteins for a class IV chitinase and an acidic glucanase in transgenic wheat plants, we regenerated a wheat line that developed necrotic lesions containing dead cells in the $T_{2}$ and subsequent generations. Lesion spots were detected at the booting stage (5- to 6-week-old plants) in lines homozygous for the transgene loci. In contrast, lesions were not observed in hemizygous transgenic lines or lines silenced for transgene expression, indicating a requirement for high levels of transgene expression for the development of the lesioned phenotype. Lesion development was associated with the accumulation of host-encoded PR proteins, e.g., chitinases, $\beta$-1,3-glucanases, thaumatinlike protein, and production of reactive oxygen intermediates. $F_{1}$ progeny of a cross between the lesion-plus transgenic line and wild-type nontransgenic plants produced progeny with a normal phenotype, while the $F_{2}$ progenies segregated for the lesion phenotype. Salicylic acid (SA) levels in plants with the lesion-plus phenotype were found to be several times higher than controls and nearly double the levels in hemizygous transgenic plants that lack lesions. SA application activated lesion development in excised leaf pieces of these hemizygous transgenic plants. Similar activation of lesion development in control plants occurred only when high concentrations of SA were applied for prolonged periods. Transcripts for phenylalanine-ammonia lyase, which provides precursors of $\mathrm{SA}$, were elevated in homozygous transgenic plants. Our data suggest that transgene-induced lesion-mimic phenotype correlates with enhanced SA biosynthesis.

Additional keywords: programmed cell death.

The first line of defense in any pathogen attack involves physical barriers (e.g., plant cell wall) and preexisting chemical barriers that are programmed to recognize the pathogen and induce defense reactions (Jayaraj et al., in press). The components of this inducible defense include: production of reactive oxygen intermediates (ROI), synthesis of phytoalexins, thickening and production of cell wall reinforcing agents (callose, hydroxy-proline rich proteins, etc.), accumulation of salicylic acid (SA), and systemic induction of a group of proteins called

Corresponding author: S. Muthukrishnan; Fax: (785)-532-7278; Telephone (785)-532-6939; E-mail: smk@ksu.edu. the pathogenesis-related (PR) proteins, such as chitinases and glucanases that exhibit antimicrobial activity (HammondKosack and Jones 1996; Ward et al. 1991; Yang et al. 1997). These responses occasionally lead to formation of necrotic spots containing dead cells that are often referred to as 'lesions' (Dangl et al. 1996). The lesions are caused by rapid death of cells at and around the infection sites and are suspected to restrict further growth and spread of the pathogen to neighboring healthy cells (Dixon and Harrison 1992). The development of lesions at the infection site in an incompatible host-pathogen interaction is often termed the hypersensitive response (HR). HR appears to be a programmed suicidal act of plant cells (Greenberg 1997) and is accompanied by accumulation of SA and PR proteins in the infected tissues (Dempsey et al. 1999). Additional signaling molecules involving jasmonic acid (JA) and its methyl ester methyl jasmonate (MeJA) are implicated to play a key role in certain pathogen-induced defense responses (Creelman and Mullet 1997).

A common goal in genetic engineering of plants for disease resistance is to enhance resistance or tolerance to various pathogens. However, expression of various foreign genes in plants has resulted in the recovery of plants with lesion-plus phenotypes (Mittler and Rizhsky 2000). Recently, Nishizawa and associates (2003) reported several phenotypic changes, including spontaneous lesion development, in transgenic rice plants constitutively expressing a rice $\beta-1,3-\beta-1,4$-glucanase transgene. Many of the lesion-containing transgenic plants had constitutively elevated levels of defenses (including PR proteins) and did not require pathogen recognition or induction of plant defenses upon infection, which is typical of the 'disease lesion mimic' mutants characterized from different plants. Most often these phenotypes show retarded growth and are often accompanied by the spontaneous formation of lesions similar to those associated with HR. Such a phenotype has been referred to as transgene-induced lesion mimic (Mittler and Rizhsky 2000; Rizhsky and Mittler 2001).

The availability of genes encoding PR proteins and the demonstration that PR proteins exhibit strong in vitro antifungal activity (Mauch et al. 1988) has led to their deployment for enhancing disease resistance in crop plants. The most commonly used approach is to constitutively express PR proteins including chitinase and $\beta$-1,3-glucanase that are known to be transcriptionally induced in many plants upon pathogen attack. Following the initial reports of significant improvement in disease resistance in transgenic plants expressing PR proteins singly or in combination (Alexander et al. 1993, Broglie et al. 
1991; Jach et al. 1995; Jongedijk et al. 1995; Lin et al. 1995; Nishizawa et al. 1999; Zhu et al. 1994), there have been numerous studies that have exploited a similar strategy (Datta et al. 1999). The result of the above studies has led to the current consensus that combinations of $\mathrm{PR}$ proteins are required to achieve effective disease control (Jayaraj et al., in press).

In this paper, we report the recovery of a lesion-mimic phenotype in a transgenic wheat line overexpressing a combination

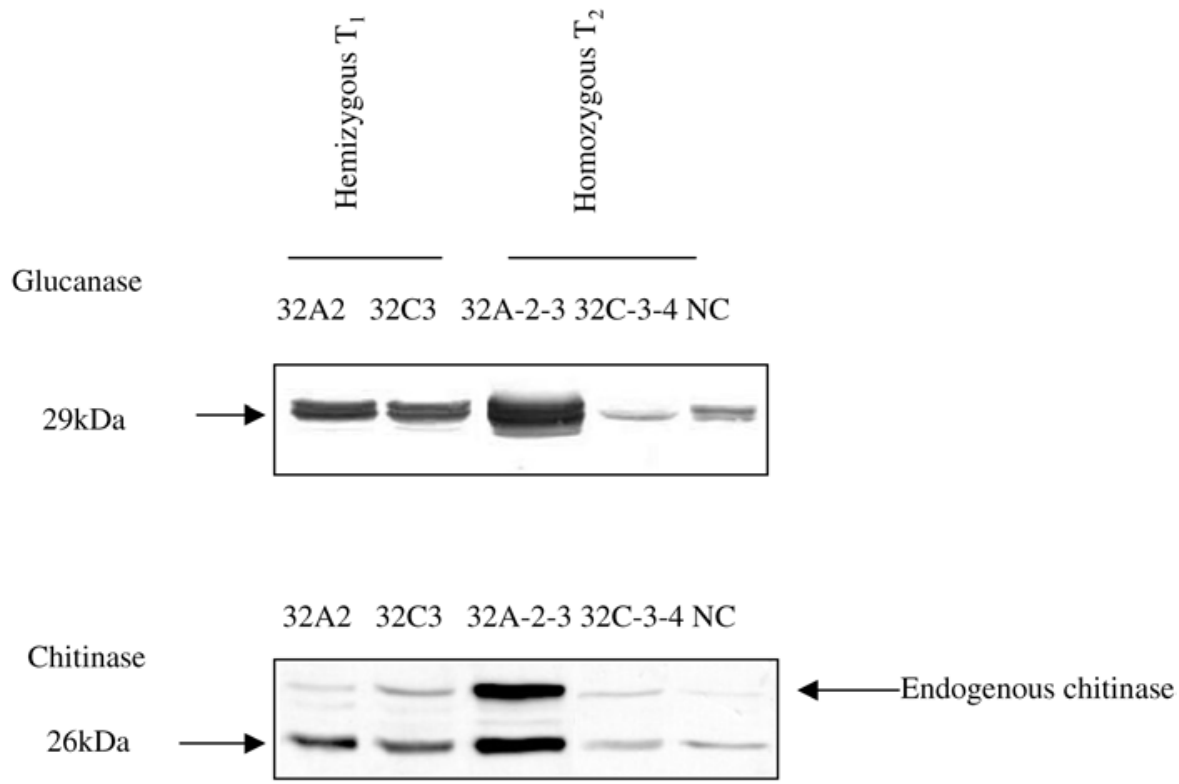

Fig. 1. Western blot analyses of transgene-encoded proteins in extracts of leaves from the expressing line and the silenced line. Crude protein extract (250 $\mu \mathrm{g}$ ) from leaf samples (5-week-old plants) were loaded in each lane and, after separation, transferred to blots. Specific polyclonal antibodies were used to detect glucanase (top panel) and chitinase (bottom panel) proteins. Lanes: 32A-2, 32C-3 hemizygous $\mathrm{T}_{1}$ parents; 32A-2-3, 32C-3-4 homozygous $\mathrm{T}_{2}$ plants; $\mathrm{NC}=$ nontransgenic control. The expected sizes of the transgene-encoded proteins are indicated by arrows on the left.

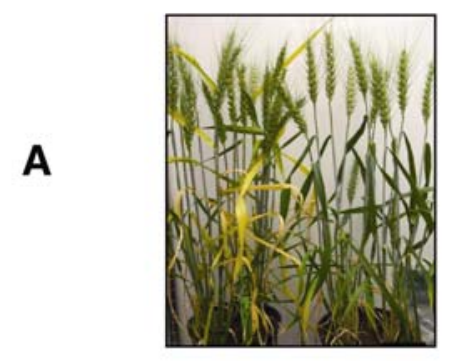

a) High expressing b) Silenced $32 \mathrm{~A}-2-3 \quad 32 \mathrm{C}-3-4$

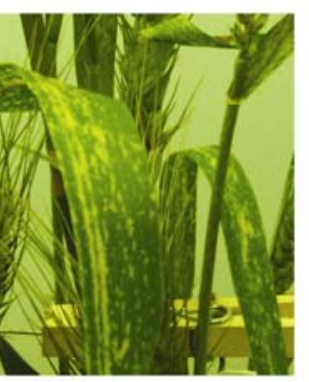

$32 \mathrm{~A}-2-3 / \mathrm{BW}+5 \mathrm{mM} \mathrm{SA}$

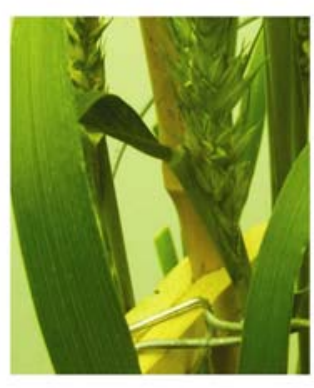

Control $+5 \mathrm{mM} \mathrm{SA}$

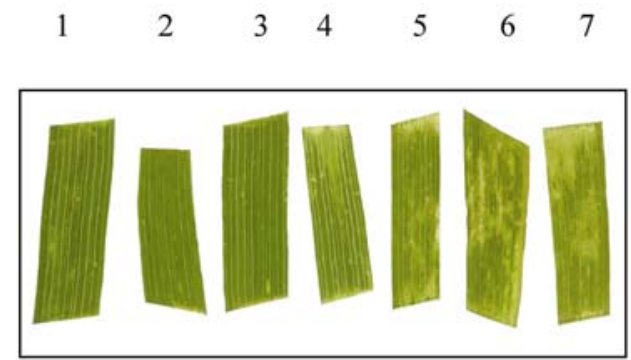

$60 \mathrm{~h}$

C

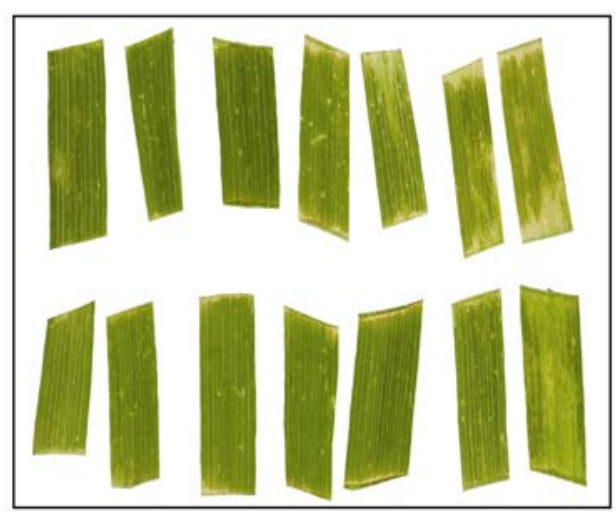

$96 \mathrm{~h}$

Fig. 2. The development of lesions in line 32A-2-3 is dependent upon transgene expression and endogenous salicylic acid (SA) levels. A, Homozygous line 32A-2-3 with complete chlorosis (on the left) and homozygous plants from line 32C-3-4 silenced for the expression of the transgene-encoded proteins with a normal phenotype (on the right). B, Treatment of the hemizygous plants and nontransgenic control plants with SA (5 mM). On the left panel, hemizygous transgenic plants with lesions and chlorotic areas $96 \mathrm{~h}$ after SA treatment. On the right panel, nontransgenic control plants $96 \mathrm{~h}$ after SA treatment. C, Treatment of leaf slices with different concentrations of SA. Observations for lesioned-areas were taken at $60 \mathrm{~h}$ of incubation (on the top row) and after $96 \mathrm{~h}$ of incubation (middle and bottom rows). Leaf pieces from hemizygous transgenic plants (top and middle row) and nontransgenic control leaves (bottom row). Lanes 1 to 7 , samples treated with different concentrations of SA ranging from 0, 0.5, 1, 2, 3, 4, and 5 mM, respectively. 
of a class IV acidic chitinase and an acidic $\beta$-1,3-glucanase. This transgenic line was studied to examine the underlying biochemical relationship between the overexpression of these transgenes and the manifestation of the lesion-mimic phenotype. Our observations suggest that overexpression of these PR protein genes is associated with accumulation of high levels of SA, production of ROI, and expression of other PR protein genes.

\section{RESULTS}

Identification of a lesion-mimic phenotype in a transgenic wheat line overexpressing a combination of wheat chitinase and glucanase transgenes.

During the analyses of several independent transgenic wheat plants transformed with genes encoding PR proteins (chitinases, glucanases, and combinations thereof), a $\mathrm{T}_{2}$ generation plant expressing high levels of a class IV wheat chitinase (383) and a wheat $\beta$-glucanase (638) with a lesion-plus phenotype (32A2\#3) was identified. This plant had all the transgenes in a single locus and expressed the transgene-encoded proteins at high levels (Anand et al. 2003a and b). Progeny derived from this plant that were homozygous for the transgene loci exhibited the lesion phenotype, whereas plants that were hemizygous for the transgene locus had the lesion-minus normal wildtype phenotype. Another homozygous transgenic line, 32C-3-4, was identified, which came from the same primary transgenic event \#32 (32A and 32C are two independent tillers derived from callus \#32), and was characterized to be genetically identical to plant \#32A-2-3 by Southern blot analyses for transgenes. The plant 32C-3-4 and its progenies had no detectable expression of the transgenes ( 383 chitinase or 638 glucanase) (Fig.1) and did not have the lesion-plus phenotype (Anand et al. 2003a). The hemizygous $\mathrm{T}_{1}$ parents, 32A-2 and 32C-3, of these transgenic plants expressed the transgene-encoded proteins (Fig. 1) and had the normal phenotype of wild-type 'Bobwhite' plants. The differences in the transgene activity in the two homozygous plants \#32A-2-3 (expressing line) and \#32C3-4 (silent line) of the $\mathrm{T}_{2}$ generation were attributed to the ex-

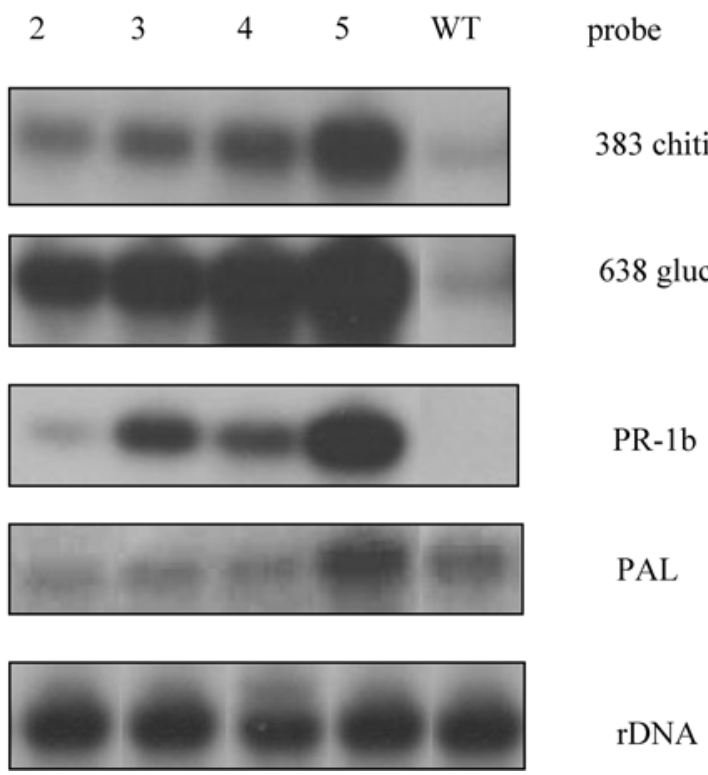

Fig. 3. RNA blots for detection of transcripts for chitinase, glucanase, and $P R-1 b$ and $P A L$ genes in the leaf samples. Leaves were sampled at weekly intervals from the lesion-mimic line starting from 2-week-old plants (with no lesion) to 5-week-old plants (with visible lesions). Total RNA $(10 \mu \mathrm{g})$ was loaded in each lane. The same RNA blot was stripped and probed sequentially with different DNA probes, as indicated on the right. tent of methylation of the CCGG sequences of the transgenes (Anand et al. 2003b).

In the homozygous plant \#32A-2-3 and its $\mathrm{T}_{3}$ progenies, visible lesions could be detected at the booting stage on the second and third leaves from the flag leaf. The lesions first appeared as small necrotic spots on the leaves. These spots later merged to form larger lesions that were observed throughout the whole plant, including the flag leaf during later stages of development. The plants bore symptoms of complete necrosis to chlorosis (Fig. 2A). This plant (\#32A-23 ) and its progeny produced normal spikes (Fig. 2A), but the phenotype affected the grain quality (lower total grain weight per 1,000 seeds) (data not shown) without affecting the fertility of the plants.

\section{Development of the lesion phenotype}

occurs only in plants homozygous for the transgene locus.

To examine whether the appearance of the lesion-mimic phenotype was a gene-dosage dependent phenomenon, homozygous plants derived from line \#32A-2-3 were crossed with wild-type nontransgenic 'Bobwhite' plants. The $F_{1}$ plants derived from the above cross were analyzed by polymerase chain reaction (PCR) for the presence of each transgene, using transgene-specific primers (data not shown). All the $\mathrm{F}_{1}$ plants had all three (383chi:638glu:bar) transgenes, displayed no lesions, and resembled the phenotype of wildtype 'Bobwhite' plants. The $\mathrm{F}_{1}$ plants were selfed, and $64 \mathrm{~F}_{2}$ plants were grown and painted with the herbicide Liberty. Segregation analyses for the transgene locus, based on the Liberty-painting assay $(0.2 \% \mathrm{vol} / \mathrm{vol})$, yielded results consistent with the predicted 3:1 ratio (bar+/bar-) for a single transgene locus for the bar gene. Fourteen of the 64 plants were found to be Liberty sensitive (i.e., bar-minus), while 17 of the remaining 50 Liberty-resistant plants gave the lesionplus phenotype. All 50 Liberty-resistant plants were analyzed by PCR and were identified to have all three transgenes (383chi:638glu:bar), as expected (data not shown). The progenies from the 17 lesion-plus plants breed true for the phenotype, whereas the progeny of the plants showing no lesions segregated for the lesion phenotype (one fourth of the progeny had lesions).

The lesion-mimic phenotype results in expression of other endogenous PR protein genes and production of reactive oxygen species (ROS).

The transcript levels of the 383 chitinase and 638 glucanase transgenes in the leaves of the transgenic line 32A-2-3 showed a gradual increase from the second to the fifth weeks of growth (Fig. 3). Maximum transcript levels for chitinase and glucanase genes were seen at the point of appearance of necrotic spots (fifth week). Additional induction of $P R$ genes was also observed in the lesion-mimic plants. The transcripts for $P R I b$ showed a gradual increase and were the highest in 5-week-old plants of line 32A-2-3, while in the nontransgenic plants (5 weeks old) there was no evidence for $P R l b$ transcripts (Fig. 3).

With progression of necrosis, there was increased expression of PR proteins, including chitinases, glucanases, and thaumatin-like proteins (TLP) (Fig. 4). The increased expression was not limited to the transgene-encoded proteins. Additional isoforms of these proteins encoded by host genes were also detected in the protein samples from 7-week-old plants (Fig. 4). The levels of expression of these PR proteins corresponded with development of lesions, and maximum levels of these proteins were observed at full blown necrosis stage (Fig. 4).

Because of the known role of ROS during HR and in cells undergoing programmed cell death, we further investigated the production of $\mathrm{H}_{2} \mathrm{O}_{2}$ at weekly intervals from the time of ap- 
pearance of microscopic lesions to complete necrosis in the lesion-mimic plants. HR was first detected as browning of the cells around the visible necrotic spots at five weeks, the earliest stage of development of lesions indicative of $\mathrm{H}_{2} \mathrm{O}_{2}$ production (Fig. 5B). Analyses of leaf samples in subsequent weeks detected coalescence of the stained cells, resulting in larger stained areas around the lesions in the six-week samples (Fig. 5C). However, leaves examined from an earlier stage (third week) failed to detect brown spots, suggesting that the production of $\mathrm{H}_{2} \mathrm{O}_{2}$ was dependent upon development and progression of necrosis (Fig. 5A). The production of $\mathrm{H}_{2} \mathrm{O}_{2}$ was initially seen on the second to third leaves from the flag leaf. In later stages of plant growth, $\mathrm{H}_{2} \mathrm{O}_{2}$ production was detected in the flag leaves, too (data not shown), which parallels our observation on appearance of visible lesions in the flag leaf.

Transgenic (chi/glu) plants accumulate higher levels of SA.

The tissues surrounding hypersensitive cell death in particular are known to accumulate transcripts for $P A L$ (Hahlbrock and Scheel 1989), a key enzyme of the phenylpropanoid pathway involved in the biosynthesis of SA from trans-cinnamic acid and other phenolic compounds in plants (Bowles 1990; Raskin 1992; Silverman et al. 1995). This prompted us to investigate the levels of $P A L$ transcripts in the homozygous lesion-plus line, starting from 2-week-old plants (no visible lesions) to 5-week-old plants (with visible lesions). The transcripts for $P A L$ showed a very marginal increase up to the

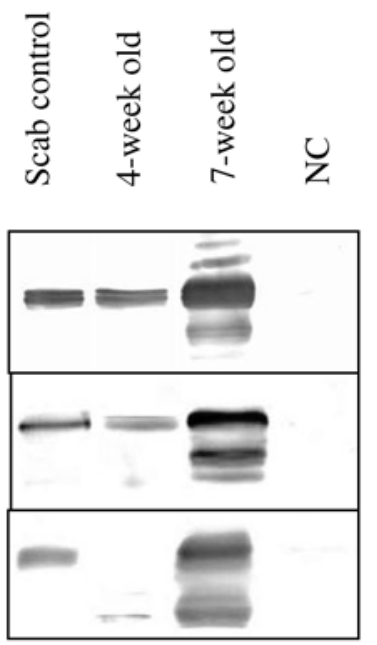

638 glucanase

383 chitinase

TLP

Fig. 4. Western blot analysis of pathogenesis-related proteins in leaf extracts of line 32A-2-3 with the lesion phenotype. Leaves from a pool of six plants were sampled before the emergence of lesions (4-week-old plants) and upon complete necrosis (7-week-old plants). Total protein $(250 \mu \mathrm{g})$ was loaded on each lane and was detected with the indicated antibody. Lanes: positive control (scab-inoculated wheat leaves), 4-weekold plants, 7-week-old plants, and nontransgenic control (NC). fourth week of growth. The highest levels of $P A L$ transcripts were detected at the point of the emergence of visible lesions (5-week-old) (Fig. 3).

The ability of SA to induce defense responses in plants was demonstrated originally as a reduction in the number of TMVinduced lesions in tobacco plants (White 1979). Later, its role in induction of $P R$ gene expression and establishment of systemic acquired resistance (SAR) was determined (Ryals et al. 1996). Additionally, it was demonstrated that application of SA leads to necroses in normal tobacco plants (van der Straeten et al. 1995). To determine whether the appearance of the lesion phenotype in the transgenic line 32A-2-3 correlates with changes in either SA or JA, plants were examined over a timecourse between weeks 2 and 7. The levels of SA peaked transiently at the booting stage (fifth week) in the wild-type plants. At time intervals before and after this peak, SA and JA levels were very low. In contrast, the hemizygous transgenic chi/glu and the homozygous chi/glu plants exhibited sharp increases in the SA levels at booting stage, reached levels higher than controls, and remained elevated through maturity (Fig. 6A and B). The free SA levels leveled off at about $300 \mathrm{ng} / \mathrm{g}$ in the hemizygous transgenic plants and about $600 \mathrm{ng} / \mathrm{g}$ in the homozygous chi/glu transgenic plants (Fig. 6A). Similarly, the homozygous chi/glu plants showed about a 10 -fold increase in conjugated SA levels by the sixth week and about a sixfold increase in the hemizygous chi/glu plants, compared with control plants at the same stage of growth. There were slight differences in the trend over the increase in conjugated SA levels in the homozygous versus hemizygous chi/glu plants. The homozygous chi/glu plants showed an increase in conjugated SA levels starting from the fourth week onward, while this trend was limited to about the fifth week in the hemizygous chi/glu plants. The elevated levels of SA in transgenic plants, especially in the lesion-plus plants, and increased gene transcripts for $P A L$ are consistent with the suggested role of SA in SAR (Enyedi et al. 1992).

Since there is evidence suggesting an intricate signaling network involving SA and JA in the fine tuning of plant defenses (Niki et al. 1998; Rao et al. 2000), we decided to determine the JA levels in the homozygous transgenic plants at weekly intervals. No large differences in JA levels were observed between homozygous chi/glu transgenic and the wild-type plants, except at the booting stage (Fig. 6C). This prompted us not to investigate the JA levels in the hemizygous transgenic plants. These results are in accordance with the postulation that JA may have a role in modifying the SA-induced activation of PR proteins in the lesion-mimic mutants (cpr1, cpr5, cpr6, coil, and ssil) of Arabidopsis (Clarke et al. 2000; Kloek et al. 2001; Nandi et al. 2003).

\section{Involvement of SA and JA signaling in the induction of lesion phenotype.}

The accumulation of many PR proteins and additional isoforms and the development of the lesion phenotype in homozy-

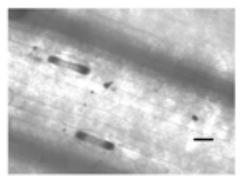

A

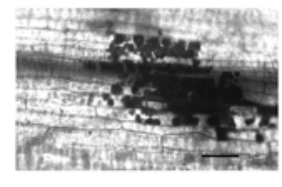

B

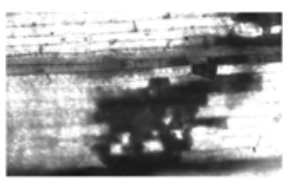

C

Fig. 5. Detection of hydrogen peroxide in the leaves of the lesion-mimic plant. Pooled leaf samples from six plants were cut into pieces of 4 to 5 cm each and were fixed and stained with diaminobenzidine. Micrographs were obtained, using transmitted light under a microscope (40× objective lens). A, No stained cells could be detected in the 3-week-old samples (the stomatal cells are seen as stained spots). B, Small areas of intense brown staining was evident in the mesophyll cells, with the production of $\mathrm{H}_{2} \mathrm{O}_{2}$ in the 5-week-old samples. $\mathbf{C}$, The area with intense staining increased further as the lesions progressed in the subsequent weeks (sixth week). Due to the deformity of the leaves undergoing necrosis, the areas with larger lesions were not in focus. Bar $=100 \mu \mathrm{m}$. 
gous plants at times when the SA levels were the highest prompted us to investigate further the role of SA and JA in these processes. In the first experiment, young plants (2 to 3 weeks old) were used. An increase in levels of chitinases, glucanases, and their isoforms was detected in the homozygous line 32A-2-3, after $24 \mathrm{~h}$ of treatment with SA (Fig. 7). Maximum levels of both the PR proteins and their isoforms were seen in the SA-treated line 32A-2-3 by $48 \mathrm{~h}$. The control plants (wild-type plants and the silenced line 32C-3-4) (data not shown) also showed an increase in the levels of chitinases and glucanases upon treatment with SA within 24 to $48 \mathrm{~h}$, but the levels reached were significantly lower than the levels reached in the 32A-2-3 line. Treating the plants with MeJA resulted in low levels of induction of chitinase and glucanase, and fewer isoforms of chitinases were detected, unlike the results observed with SA treatments (Fig. 7) in the transgenic line 32A2-3. SA treatment of young plants that were homozygous for the transgene loci or of the control plants did not result in the development of lesions, even after several days.

SA treatment of hemizygous transgenic plants of \#32A-2-3 at the booting stage resulted in the formation of distinct ne- crotic patches and chlorotic zones similar to those seen in homozygous transgenic plants within $96 \mathrm{~h}$ after treatment (Fig. 2B). The nontransgenic control plants and the silenced plants (line 32C-3-4) did not develop lesions, even after several days following the SA treatment. The levels of chitinase and glucanase proteins were drastically increased after $48 \mathrm{~h}$ of treatment with SA in these hemizygous plants. The expression of the other isoforms of these PR proteins was also detected in the same protein samples (48-h samples) (Fig. 8). The nontransgenic plants (Fig. 8) and the silenced line (data not shown) showed increases in the expression levels of chitinases and glucanases after $48 \mathrm{~h}$ of SA treatment that were significantly lower than those detected in the hemizygous plants treated with SA for the same length of time. In contrast, treatment of the hemizygous plants ( $\mathrm{F}_{2}$ plants of the $32 \mathrm{~A}-2-3 / \mathrm{BW}$ cross) with MeJA did not result in the induction of chitinases and glucanases (transgenic or endogenous) (data not shown). There was also no evidence of lesion development, even after several days of MeJA treatment. We further investigated the induction of TLP in the hemizygous plants treated with SA, as a measure of induction of an endogenous PR protein gene. The level of
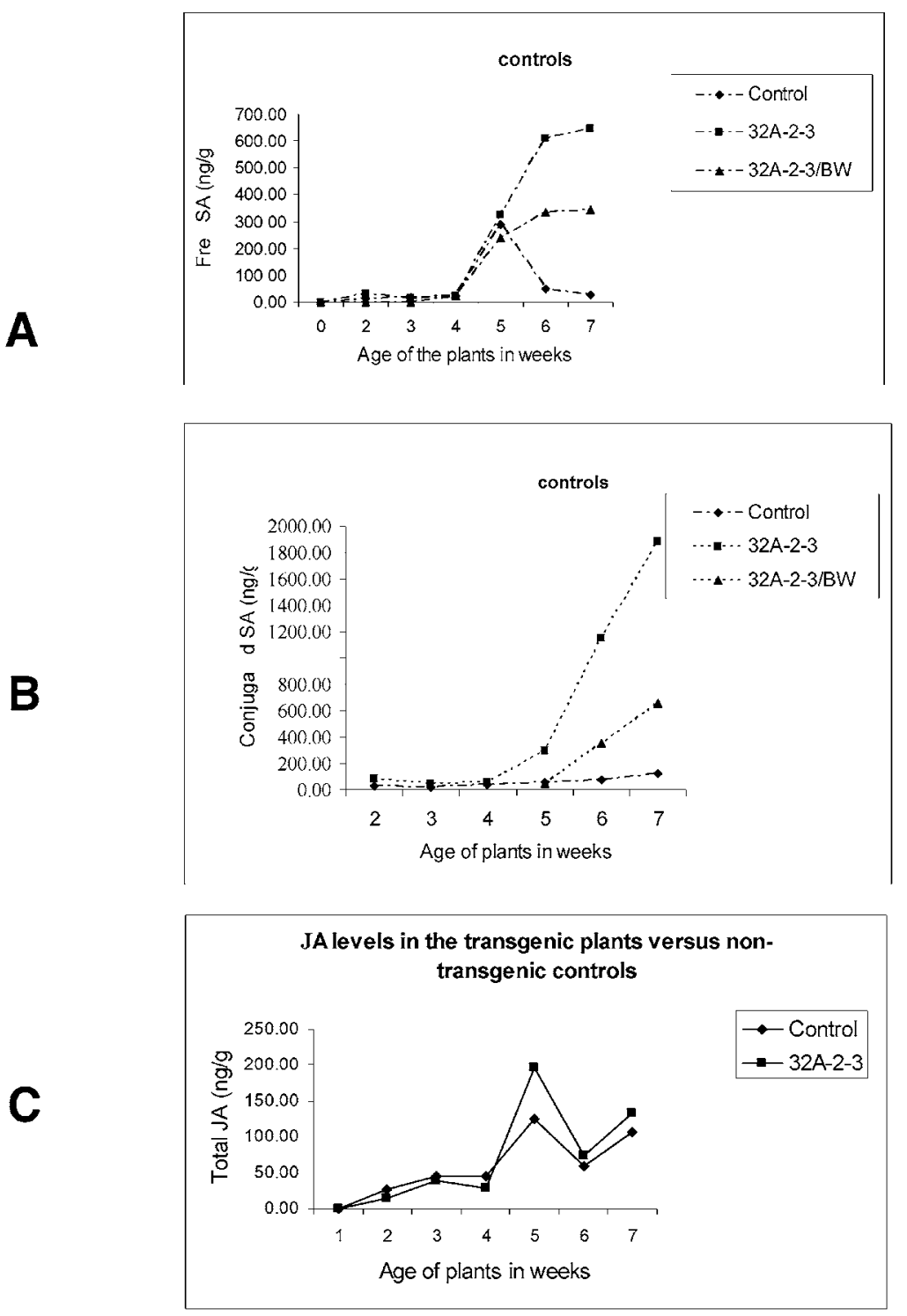

Fig. 6. A, Estimation of free salicylic acid (SA); B, conjugated SA; and C, total jasmonic acid (JA) levels in wheat plants. Leaf samples were randomly pooled from 10 plants at similar physiological growth at weekly intervals starting from the second week to the seventh week. $\mathrm{C}=$ nontransgenic controls; $\mathrm{TC}=$ homozygous $c h i / g l u$ plants and $\mathrm{H}=$ hemizygous chi/glu plants. 
this protein in the hemizygous plant was comparable to that of the level in the nontransgenic plant prior to SA treatment. A substantial increase in TLP levels was detected in the samples of the hemizygous transgenic plants collected at $48 \mathrm{~h}$ after SA treatment (Fig. 8). No such increase was seen in the control plants treated with SA.

The influence of SA concentration on the induction of lesions in the hemizygous plants was further investigated. Within $60 \mathrm{~h}$ of incubation, lesions were detected in the hemizygous plants treated with $1 \mathrm{mM}$ or more of SA. Necrotic areas were seen in the leaf samples of the hemizygous plants treated with $2,3,4$, and $5 \mathrm{mM} \mathrm{SA}$. The severity of the lesions was dependent upon the concentration of SA applied (Fig. 2C). After $84 \mathrm{~h}$ of incubation, complete chlorosis along the cut ends of the leaves was visualized in hemizygous plants $(3,4$, and $5 \mathrm{mM})$. Lesions were also seen in leaf pieces from control plants incubated with 4 or $5 \mathrm{mM} \mathrm{SA}$, even though the lesions appeared later $(96 \mathrm{~h})$ and were less numerous than in the transgenic plants (Fig. 2C).

\section{DISCUSSION}

Constitutive overexpression of the chi383 and glu638 transgenes in a transgenic wheat line (32A-2-3) was associated with a lesion-mimic phenotype in progeny plants of the $\mathrm{T}_{2}$ or later generations. Further, the lesions appeared only when the transgene-encoded proteins were expressed, since the silenced line 32C-3-4 did not exhibit lesions, suggesting that the lesion phe-
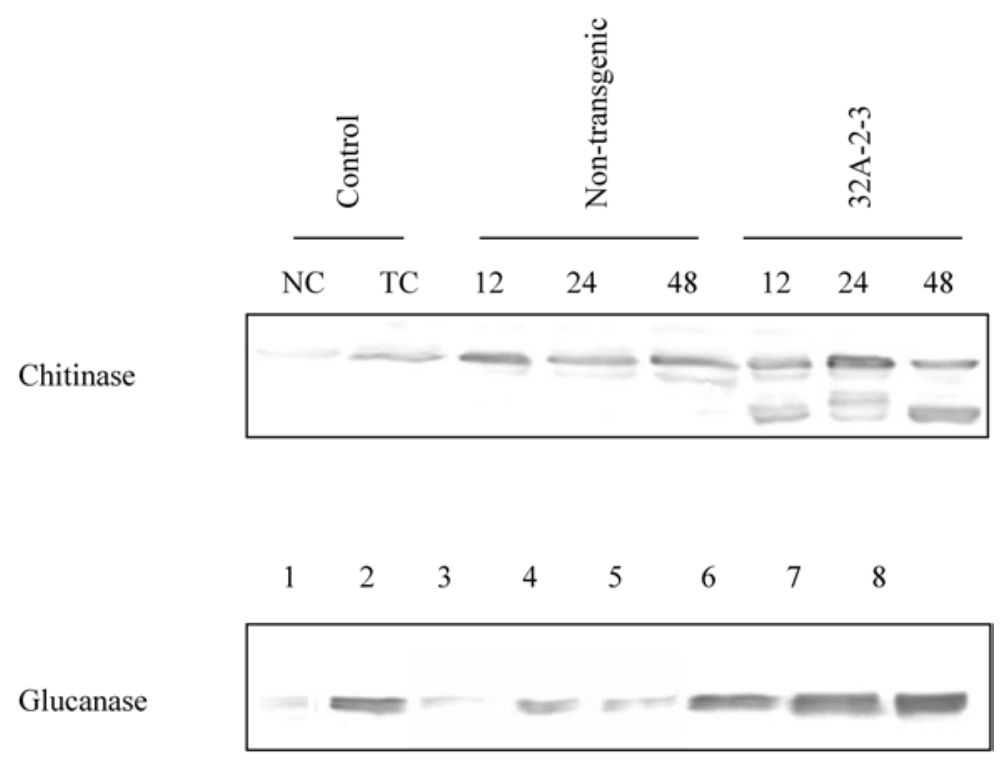

Fig. 7. Chitinase and glucanase levels in lesion-mimic and wild-type plants upon treatment with salicylic acid. Lanes: NC and TC, 0-h controls for nontransgenic and 32A-2-3 plants, respectively; first set of lanes = 12-, 24-, and 48-h samples from nontransgenic control plants; and second set of lanes = 12-, 24-, and 48-h samples from line \#32A-2-3.

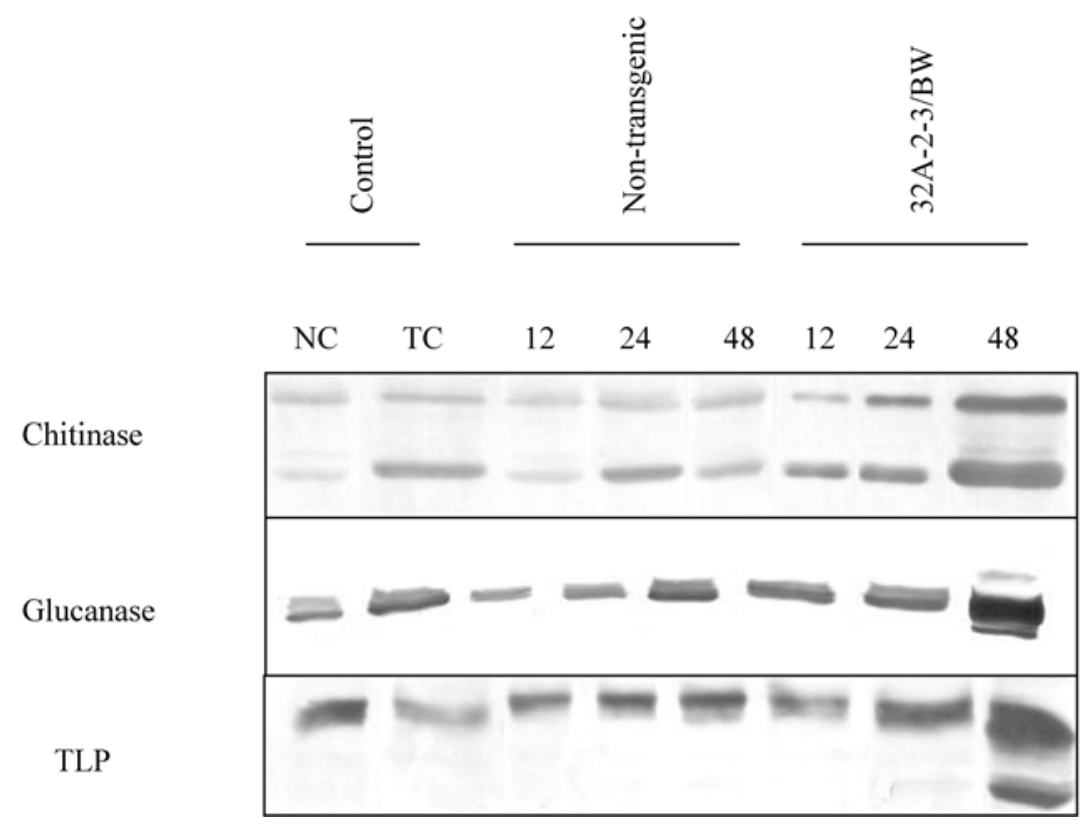

Fig. 8. Levels of chitinase, glucanase, and thaumatin-like proteins in the hemizygous 32A2/BW and nontransgenic control plants upon salicylic acid treatment. Lanes: NC and TC: 0-h controls for nontransgenic and 32A2/BW plants; first set of lanes = 12-, 24-, and 48-h samples from nontransgenic control plants; and second set of lanes = 12-, 24-, and 48-h samples from line 32A2/BW. 
notype was not due to disruption of one or more host genes at the site of transgene insertion and was dependent on transgene function. Lesions were seen only when the expression level was very high. However, we could not completely eliminate the possibility of host gene activation by transgene insertion, since another independent transgenic event expressing the same combination of chitinase (383) and glucanase (638) was not recovered. The hemizygous $\mathrm{T}_{2}$ plants, their progenies, and the hemizygous plants derived from crosses between the lesion-mimic line and wild-type nontransgenic plants, which had lower expression levels (probably half) of the transgeneencoded proteins compared with homozygous plants, did not exhibit the lesion-mimic phenotype (Fig. 1). Inspection of the seedlings during germination and the early-growth phase (4week-old plants) showed that the constitutive expression of the combination of these PR protein genes did not result in any visible changes in morphology or growth characteristics of these plants compared with nontransgenic controls. Bliffeld and associates (1999) reported that they could not recover transgenic wheat plants expressing a barley $\beta$-1,3-glucanase, and attributed this failure to a harmful effect of $\beta$-glucanase gene expression on callus growth and regeneration of the transgenic plants. Our successful regeneration of independent transgenic plants with high level expression of $\beta$-glucanase indicates that this may not be the case. Nevertheless, the finding that one transgenic line with very high levels of $\beta$-glucanase and chitinase has a lesion-mimic phenotype does suggest that there may be some adverse effect of overexpression of a $\beta-1,3-$ glucanase gene. Furthermore, while overexpressing a stressinducible $\beta$-1,3;1,4-glucanase gene Gnsl (encoding an enzyme capable of hydrolyzing a mixed barley $\beta$-glucan from barley) in transgenic rice, Nishizawa and associates (2003) recovered several transgenic plants with a lesion-mimic phenotype. Interestingly, the development of lesions in these plants was also dependent on the growth stage of the transgenic rice plants (within 5 to 6 weeks after transplanting, which coincides with the booting stage). It is not clear whether new substrates for the $\beta$-1,3-glucanase appear in wheat plants at the booting stage. Cereal aleurone and endosperm cell walls are known to have $\beta-1,3 ; 1,4$-glucans but no $\beta$-1,3-glucan (Gibeaut and Carpita 1993; Lai et al. 1993; Woodward and Fincher 1983). Callose (a $\beta$-1,3-glucan polymer) is found in the cell walls of microspores of tetrads, and a developmentally controlled $\beta$-1,3-glucanase is induced in higher plants (Leubner-Metzger and Meins 1999). The appearance of lesions only during the booting stage in transgenic plants overexpressing the chitinase and $\beta$-1,3-glucanase may be related to the appearance of endogenous substrates for one or both of these PR proteins.

The lesions seen in the transgenic plants overexpressing the genes for PR proteins are similar to the ones triggered during HR in incompatible interactions of plants and pathogens (Dangl et al. 1996; Hammond-Kosack and Jones 1996; Lamb and Dixon 1997; Yang et al. 1997). The production of a transgene-induced lesion-mimic phenotype was reviewed by Mittler and Rizhsky (2000). A key to understanding transgene-induced lesion mimics is to study their naturally occurring counterparts (lesion mutants) found in different plants (Bowling et al. 1994; Jirage et al. 2001; Walbot et al. 1983; Wolter et al. 1993). Based on the appearance and progression of the phenotype, lesion mutants can be classified into two groups: initiation and propagation mutants (Dietrich et al. 1994; Greenberg et al. 1994; Mittler and Rizhsky 2000; Walbot et al. 1983). The initiation mutants are postulated to lack a negative regulator of HR activation (recessive mutant) or to have a constitutively activated HR signal component (dominant mutant). Propagation or feedback mutants develop spontaneous or induced lesions that propagate uncontrollably, eventually resulting in the complete death of the leaf. These mutants are presumed to be defective in down-regulating the process of lesion progression. The transgenic wheat plants expressing the chi/glu transgenes reported here appear to fall in the propagation class of lesion mutants. The lesions appear spontaneously and spread throughout the leaf, without affecting the fertility of the plants. The timing and pattern of propagation of the lesions suggests that the overexpression of the combination of chi/glu transgenes may have resulted in activation of the HR-like programmed cell death (PCD) pathway, which was reported in transgeneinduced lesion mimics (Fiore et al. 2002; Mittler et al. 1995; Molina et al. 1999b; Nishizawa et al. 2003; Pontier et al. 2002; Rizhsky and Mittler 2001; Takahashi et al. 1997).

Overexpression of transgenes in line 32A-2-3 results in the turning on of other $P R$ protein genes and production of ROS that are indicators of progressive cell death in plants. The increased $P A L$ gene transcripts and the supporting data on increased SA levels in the lesion-mimic plants suggest that the introduction and overexpression of the combination of genes for PR proteins resulted in spontaneous activation of several different components of the plant defense mechanism. Spraying of SA failed to induce the lesion-plus phenotype in the young plants of homozygous line 32A-2-3 at an earlier stage of their growth. However, spraying the hemizygous plants with similar concentrations of SA $(5 \mathrm{mM})$ resulted in the recovery of the lesion phenotype at the booting stage. Further, the PR proteins in the homozygous line 32A-2-3 (2 to 3 weeks old) treated with SA never reached the levels detected in the lesionplus phenotype plants or those seen in the hemizygous plants at the booting stage upon treatment with SA, suggesting that certain threshold levels of these proteins may be required for signaling the PCD pathway. These findings demonstrate that both the physiological state of growth and SA levels are critical in production of the lesions.

Free SA accumulates transiently in control plants around booting stage, but in transgenic plants with high levels of chitinase and glucanase, levels of free SA continued to increase in hemizygous and homozygous plants, respectively. Similarly, the conjugated SA levels increased from the fourth to the seventh weeks (from $293 \mathrm{ng} / \mathrm{g}$ to $1,888 \mathrm{ng} / \mathrm{g}$ ) in the homozygous plants, while the increase in the conjugated SA levels in the hemizygous plants ranged anywhere between $50 \mathrm{ng} / \mathrm{g}$ (fifth week) to $656 \mathrm{ng} / \mathrm{g}$ (seventh week). The increased expression of transgenes and increased total SA levels and the appearance of lesions suggest the possibility for transgene interaction with SA signaling. This hypothesis is supported by the observation that the lesion phenotype could be induced in both hemizygous and control transgenic plants and leaf sections upon exposure to exogenous SA. The hemizygous plants, which have an intermediate level of free SA, required a lower concentration and shorter incubation time compared with nontransgenic controls for lesion development.

Earlier reports using chemical activators of SAR, such as SA, 2,6-dichloro isonicotinic acid (INA), or benzo(1,2,3)thiadiazole-7-carbothioic acid S-methyl ester (BTH) in wheat (Görlach et al. 1996; Molina et al. 1999a; Schaffrath et al. 1997), suggested that the pathogen-inducible genes (biological agents) and chemical-inducible genes (chemical agents) were activated by different signaling pathways in wheat. Our results, involving both transgenic wheat and control wild-type plants sprayed with SA $(5 \mathrm{mM})$, did show induction, enhanced levels, or both of PR2 ( $\beta$-1,3-glucanase), PR3 (chitinase), and PR5 (TLP) proteins. Similar results were observed when SA was applied intercellularly to wheat cultivars resistant to Russian wheat aphid (RWA), using peroxidase as the defense marker gene (Mohase and van der Westhuizen 2002). The increased expression of these PR pro- 
teins in our study was also accompanied by the appearance of the lesion-plus phenotype in the hemizygous plants sprayed with SA. In control plants treated with SA, a concentration and time-dependent occurrence of lesions was observed, using a leaf disk assay. Therefore, the failure to observe induction of pathogen-inducible genes treated with SA and INA reported earlier in wheat (Görlach et al. 1996; Molina et al. 1999a; Schaffrath et al. 1997) might be due to differences in the concentration of SA applied, as in our study $(5 \mathrm{mM})$, the method of SA application, or both.

Some lesion-mimic plants, including rice plants overexpressing a $\beta$-1,3;1,4-glucanase gene, show enhanced resistance to pathogens (Mittler and Rizhsky 2000; Nishizawa et al. 2003). Interestingly, both the homozygous (32A-2-3) and hemizygous plants with high levels of expression for transgenes and elevated SA levels were more resistant than nontransgenic controls to Fusarium graminearum in greenhouse studies. It also seems that SA accumulation is involved in the induction of defense responses in the RWA-wheat interaction (Mohase and van der Westhuizen 2002). Therefore, SA appears to be an important component of acquired resistance in wheat plants; however, the mode of SA activation and their role in the induction of defense responses still needs elucidation in this crop.

Expression of the PR protein genes, elevation of SA levels, or both are critical in the production of the lesion-mimic phenotype in line 32A-2-3. However, the precise relationship and interactions between PR proteins and SA are not clear. The increased levels of $P A L$ transcripts and the increase in total and free SA levels suggests that the SA biosynthetic pathway is enhanced in transgenic wheat plants overexpressing the chitinase and glucanase genes. Transgenic tobacco plants expressing vacuolar and apoplastic yeast-derived invertase genes (Herber et al. 1996) or overexpressing a proton-pump (bO) transgene (Mittler et al. 1995) also exhibit slightly increased transcripts for the PAL gene. These transgenic tobacco plants also developed spontaneous lesions and had elevated levels of SA. Therefore, it would be interesting to investigate additional transgenic lines with similar levels of expression of the chi/glu transgenes and other combinations involving different classes of chitinases and glucanases for understanding the lesion phenomenon in transgenic plants. Additional genetic and biochemical analyses will provide insights to the development of the lesion-mimic phenotype.

The PCD pathway in plants in response to a pathogen attack or under any physiological stress is not clearly understood. In this paper, we used a lesion-mimic transgenic plant as a model to explore and demonstrate that overexpression of $P R$ genes in plants could trigger the PCD pathway under normal growth conditions. Overexpression per se appears to have served as a stress at a certain physiological stage of growth that resulted in increased SA levels in these plants. Although the precise signals for activation of PCD in these plants remains unclear, our results suggest that this pathway is critically influenced by total and free SA levels. To our knowledge, this is the first report of SA-dependent regulation of PR protein gene expression in wheat.

\section{MATERIALS AND METHODS}

\section{Construction of transformation cassettes and characterization of transgenic plants.}

The construction of the transformation cassettes for constitutive expression of a class IV chitinase (chi 383) and an acidic glucanase ( lu 638) gene (under the control of maize ubiquitin intron-promoter) has been described previously (Anand et al. 2003a). The putative transgenic plants and their progenies were analyzed for the presence of the bar gene (selectable marker) and its expression, using the leaf-painting assay with $0.2 \%$ Liberty herbicide. Further molecular characterization of these plants for the presence and expression of the genes of interest using DNA blot analyses, RNA blot analyses, and PR protein analysis by immunoblotting was as described in Anand and associates (2003a and b). In the course of characterizing different transgenic events and their progenies, line 32A-2 and line 32C3 , which are genetically identical and express a combination of a class IV chitinase (383 chitinase) and an acidic $\beta-1,3-$ glucanase (638 glucanase), were identified (Anand et al. $2003 b$ ). Further characterization of the progenies derived from plants $32 \mathrm{~A}-2$ and $32 \mathrm{C}-3$ resulted in the identification of the homozygous lines 32A-2-3 and 32C-3-4. The plant 32A-2-3 and its progenies showed high levels of expression for transgeneencoded proteins and produced a lesion-mimic phenotype and breed true for the phenotype for several generations (characterized to the $\mathrm{T}_{5}$ generation). The plant 32C-3-4 and its progenies were either completely silenced or showed significantly lower levels of expression of the transgene-encoded proteins and produced normal wild-type phenotype.

\section{Plant treatments and their biochemical characterization.}

Wheat plants (Triticum aestivum L. cv. Bobwhite) were grown in growth chambers with a 16-h light period, at a light intensity of $600 \mu \mathrm{E} / \mathrm{m}^{2} / \mathrm{s}$ and a temperature regime of $20: 18^{\circ} \mathrm{C}$ (light/dark). Leaves of the transgenic plants (from 2 to 7 weeks old) that were homozygous or hemizygous for the transgene loci and control nontransgenic plants were harvested, and tissue samples for SA, JA, RNA blot, and PR protein analyses were stored at $-70^{\circ} \mathrm{C}$. RNA gel blots were first hybridized with the 383-cDNA coding fragment as the radioactive probe, stripped free of the radio-label, and rehybridized sequentially with the 638-cDNA coding fragment probe, followed by the $P R 1 b$ probe and the $P A L$ cDNA coding fragment probe from wheat (provided by N. Sakthivel, Kansas State University), and then, finally, with the probe for 18S rRNA. For Western blot analyses, polyclonal antibodies raised in rabbits against a barley chitinase (Swegle et al. 1992), a barley $\beta$-1,3-glucanase (a gift from M. Ballance, University of Manitoba, Winnipeg, Canada), or a pinto bean TLP (Sehgal et al. 1991), respectively, were used. As the positive control, leaf protein extract from wheat plants inoculated with Fusarium graminearum (scab) was used. For the analyses of $\mathrm{H}_{2} \mathrm{O}_{2}$ production in the lesionplus plants, seeds from the homozygous line (32A-3-3) were staggered and germinated, and leaves were sampled from 2- to 7-week-old plants. The in vivo detection of $\mathrm{H}_{2} \mathrm{O}_{2}$ release during different stages of lesion development in the transgenic plants was carried out using 3,3'-diaminobenzidine- $\mathrm{HCl}, \mathrm{pH}$ 3.8 (Sigma, St. Louis), according to Thordal-Christensen and associates (1997). For estimating the SA (free and conjugated forms) and total JA levels, leaves were bulked from 10 plants of similar physiological growth at weekly intervals. Tissue samples (200 mg) were analyzed for free SA, conjugated SA, and JA, as described by Engelberth and associates (2003). Reported JA levels represent the summation of both cis and trans isomers.

\section{SA and MeJA treatments.}

For SA treatment, the transgenic plants and control plants were sprayed with an aqueous solution of $5 \mathrm{mM} \mathrm{SA}, \mathrm{pH} 7.0$ (Sigma) containing $0.2 \%$ ( $\mathrm{vol} / \mathrm{vol})$ Tween-20 until run-off (Dietmar and Weiler 1998). Treatments of plants with MeJA ( $50 \mu \mathrm{M}$ in $0.1 \%$ ethanol) were performed as described by Mittler and associates (1995). Leaf samples were harvested at 0 (control), 12, 24, and $48 \mathrm{~h}$ after SA or MeJA treatment, for PR protein analyses. Similarly, transgenic homozygous (2 weeks old), hemizygous plants (at booting stage), and control non- 
transgenic plants at similar stages of development were treated with $5 \mathrm{mM} \mathrm{SA}$, for recovering the lesion-mimic phenotypes. For the experiments with leaf blades, healthy leaves from mature plants of the hemizygous transgenic lines and control nontransgenic plants were collected and cut into 1-inch long pieces and were incubated at different concentrations of SA $(0,0.5,1$, $2,3,4$, and $5 \mathrm{mM}, \mathrm{pH} 7.0$ ). Visual observations were recorded at 12-h intervals, until necrotic areas were detected in the transgenic and control plants.

\section{Crossing the lesion-mimic plants with nontransgenic control plants.}

Homozygous $\mathrm{T}_{3}$ plants of line 32A-2-3 were crossed with nontransgenic control 'Bobwhite' plants for analyses of the inheritance of the lesion-mimic phenotype. The $F_{1}$ seeds recovered from these crosses were germinated and were painted with a freshly prepared aqueous solution of Liberty herbicide $(0.2 \%$ $\mathrm{vol} / \mathrm{vol}$ ), to examine the expression of the bar gene in the $\mathrm{F}_{1}$ progeny of this cross. The presence of one or more transgenes in the genomic DNA was detected by PCR using transgenespecific primers, and Western blot analyses were carried out with protein extracts of the $F_{1}$ plants (Anand et al. 2003a). The $\mathrm{F}_{2}$ seeds were bulked and germinated. Further molecular characterization based on the Liberty painting assay, appearance of the lesion phenotype, and PCR detection of the transgenes was used to confirm the genotype of each plant.

\section{ACKNOWLEDGMENTS}

The authors thank H. Trick and the plant transformation group at Kansas State University for their assistance with wheat transformation. The research input from B. S. Gill and J. Shah in designing some of the experiments is highly appreciated. We are grateful to J. Shah, J.-M. Zhou and J. Leach for critically reviewing the manuscript. This research was funded in part by the Kansas Wheat Commission and the U.S. Wheat and Barley Scab Initiative. This is contribution \#03-316-J of the Kansas Agricultural Experiment Station.

\section{LITERATURE CITED}

Alexander, D., Goodman, R. M., Gut-Rella, M., Glascock, C., Weymann, K., Friedrich, L., Maddox, D., Ahl-Goy, P., Luntz, T., Ward, E., and Ryals, J. 1993. Increased tolerance to two oomycete pathogens in transgenic tobacco expressing pathogenesis-related protein 1a. Proc. Natl. Acad. Sci. U.S.A. 90:7327-7331.

Anand, A., Zhou, T., Bockus, B., Muthukrishnan, S., Trick, H. N., and Gill, B. S. 2003a. Greenhouse and field testing of transgenic wheat plants stably expressing genes for thaumatin-like protein, chitinase and glucanase against Fusarium graminearum. J. Exp. Bot. 54:1101-1111.

Anand, A., Trick, H. N., Gill, B. S., and Muthukrishnan, S. 2003b. Stable transgene expression and random gene silencing in wheat. Plant Biotech. J. 1:241-252.

Bliffeld, M., Mundy, J., Potrykus, I., and Futterer, J. 1999. Genetic engineering of wheat for increased resistance to powdery mildew disease. Theor. Appl. Genet. 98:1079-1086.

Bowles, D. J. 1990. Defense-related proteins in higher plants. Annu. Rev. Biochem. 59:873-907.

Bowling, S. A., Guo, A., Cao, H., Gordon, A. S., Klessig, D. F., and Dong, X. 1994. A mutation in Arabidopsis that leads to constitutive expression of systemic acquired resistance. Plant Cell 6:1845-1857.

Broglie, K., Chet, I., Holliday, M., Cressman, R., Biddle, P., Knowlton, S., Mauvais, J., and Broglie, R. M. 1991. Transgenic plants with enhanced resistance to the fungal pathogen Rhizoctonia solani. Science 254:1194-1197.

Clarke, J. D., Volko, S. M., Ledford, H., Ausubel, F. M., and Dong, X. 2000. Roles of salicylic acid, jasmonic acid, and ethylene in cpr-induced resistance in Arabidopsis. Plant Cell 12:2175-2190.

Creelman, R. A., and Mullet, J. E. 1997. Biosynthesis and action of jasmonates in plants. Annu. Rev. Plant Physiol. Plant Mol. Biol. 48:355381.

Dangl, J. L., Dietrich, R. A., and Richberg, M. H. 1996. Death don't have no mercy: Cell death programs in plant-microbe interactions. Plant Cell 8:1793-1807.
Datta, K., Muthukrishnan, S., and Datta, S. K. 1999. Pages 261-277 in: Pathogenesis-Related Proteins in Plants. S. K. Datta and S. Muthukrishnan, eds. CRC Press, Boca Raton, FL, U.S.A.

Dempsey, D. A., Shah, J., and Klessig, D. F. 1999. Salicylic acid and disease resistance in plants. Crit. Rev. Plant Sci. 18:545-575.

Dietmar, L., and Weiler, E. W. 1998. Allene oxide synthase: A major control point in Arabidopsis thaliana octadecanoid signaling. Plant J. 15:675-684.

Dietrich, R. A., Delany, T. P., Uknes, S. J., Ward, E. R., Ryals, J. A., and Dangl, J. L. 1994. Arabidopsis mutants simulating disease resistance response. Cell 77:565-577.

Dixon R. A., and Harrison M. J. 1992. Activation, structure and organization of genes involved in microbial defense in plants. Adv. Genet. 28:165-234.

Engelberth, J., Schmelz, E. A., Alborn, H. T., Cardoza, Y. J., Huang, J., and Tumlinson, J. H. 2003. Simultaneous quantification of jasmonic acid and salicylic acid in plants by vapor-phase extraction and gas chromatography-chemical ionization-mass spectrometry. Anal. Biochem. 312:242-250.

Enyedi, A. J., Yalpani, N., Silverman, P., and Raskin, I. 1992. Signal molecules in systemic plant resistance to pathogens and pests. Cell 70:879-886.

Fiore, S. D., Li, Q., Leech, M. J., Schuster, F., Emans, N., Fischer, R., and Schillberg, S. 2002. Targeting tryptophan decarboxylase to selected subcellular components of tobacco plants affects enzyme stability and in vivo function and leads to a lesion mimic phenotype. Plant Physiol. 129:1160-1169.

Gibeaut, D. M., and Carpita, N. C. 1993. Synthesis of (1-3), (1-4) $\beta$-Dglucan in the Golgi apparatus of maize coleoptiles. Proc. Natl. Acad. Sci. U.S.A. 90:3850-3854.

Görlach, J., Volrath, S., Knauf-Beiter, G., Hengry, G., Beckhove, U., Kogel, K.-H., Oostendorp, M., Staub, T., Ward, E., Kessmann, H., and Ryals, J. 1996. Benzothiadiazole, a novel class of inducers of systemic acquired resistance, activates gene expression and disease resistance in wheat. Plant Cell 8:629-643.

Greenberg, J. T. 1997. Programmed cell death in plant-pathogen interactions. Ann. Rev. Plant Physiol. Plant Mol. Biol. 48:525-545.

Greenberg, J. T., Ailan, G., Klessig, D. F., and Ausubel, F. M. 1994. Programmed cell death in plants: A pathogen-triggered response activated coordinately with multiple defence functions. Cell 77:551-563.

Hahlbrock, K., and Scheel, D. 1989. Physiology and molecular biology of phenylproponoid metabolism. Annu. Rev. Plant Physiol. Plant Mol. Biol. 40:347-369.

Hammond-Kosack, K. E., and Jones, J. D. G. 1996. Resistance gene-dependent plant defense responses. Plant Cell 8:1773-1791.

Herber, K., Meuwly, P., Frommer, W. B., Metraux J.-P., and Sonnewald, U. 1996. Systemic acquired resistance mediated by ectopic expression of invertase: Possible hexose sensing in the secretory pathway. Plant Cell 8:793-803.

Jach, G., Gornhardt, B., Mundy, J., Logemann, J., Pinsdorf, E., Leah, R., Schell, J., and Maas, C. 1995. Enhanced quantitative resistance against fungal disease by combinatorial expression of different barley antifungal proteins in transgenic tobacco. Plant J. 8:97-109.

Jayaraj, J., Anand, A., and Muthukrishnan, S. In: Fungal Disease Resistance in Plants-Biochemistry, Molecular Biology and Genetic Engineering. P. Zamir, ed. Haworth Press, Binghamton, NY, U.S.A. In press.

Jirage, D., Zhou, N., Cooper, B., Clarke, J. D., Dong, X., and Glazebrook, J. 2001. Constitutive salicylic acid-dependent signaling in cprl and cpr6 mutants requires PAD4. Plant J. 26:395-407.

Jongedijk, E., Tigelaar, H., van Roekel, J. S. C., Bres-Vloemans, S. A., Dekker, I., van den Elzen, P J. M., Cornelissen, B. J. C., and Melchers, L. S. 1995. Synergistic activity of $\beta$-1,3-glucanases and chitinases enhances fungal resistance in transgenic tomato plants. Euphytica 85:173-180.

Kloek, A. P., Verbsky, M. L., Sharma, S. B., Schoelz, J. E., Vogel, J., Klessig, D. F., and Kunkel, B. N. 2001. Resistance to Pseudomonas syringae conferred by an Arabiopsis thaliana coronatine-insensitive (coil) mutation occurs through two distinct mechanisms. Plant J. 26:509-522.

Lai, M. L. D., Hoj, P. B., and Fincher, G. B. 1993. Purification and characterization of $(1 \rightarrow 3,1 \rightarrow 4)$ - $\beta$-glucan endohydrolases from germinated wheat (Triticum aestivum). Plant Mol. Biol. 22:847-859.

Lamb, C., and Dixon, R. A. 1997. The oxidative burst in plant disease resistance. Annu. Rev. Plant Physiol. Plant Mol. Biol. 48:251-275.

Leubner-Metzger, G., and Meins, F., Jr. 1999. Pages 49-76 in: Pathogenesis-Related Proteins in Plants. S. K. Datta and S. Muthukrishnan, eds. CRC Press, Boca Raton, FL, U.S.A.

Lin, W., Anuratha, C. S., Datta, K., Potrykus, I., Muthukrishnan, S., and Datta, S. K. 1995. Genetic engineering of rice for resistance to sheath blight. Bio/Technology 13:686-691. 
Mauch, F., Mauch-Mani, B., and Boller, T. 1988. Antifungal hydrolases in pea tissue: Inhibition of fungal growth by combinations of chitinase and $\beta$-1,3-glucanase. Plant Physiol. 88:936-942.

Mittler R., and Rizhsky, L. 2000. Transgene-induced lesion mimics. Plant Mol. Biol. 44:335-344.

Mittler, R., Shuleav, V., and Lam, E. 1995. Coordinated activation of programmed cell death and defense mechanisms in transgenic tobacco plants expressing a bacterial proton pump. Plant Cell 7:29-42.

Mohase, L., and van der Westhuizen, A. J. 2002. Salicylic acid is involved inresistance responses in the Russian wheat aphid-wheat interaction. J. Plant Physiol. 159:585-590.

Molina, A., Görlach, J., Volrath, S., and Ryals, J. 1999a. Wheat genes encoding two type of PR-1 proteins are pathogen inducible, but do not respond to activators of systemic acquired resistance. Mol. PlantMicrobe Interact. 12:53-58.

Molina, A., Volrath, S., Guyer, D., Maleck, K., Ryals, J., and Ward, E. 1999b. Inhibition of protoporphyrinogen oxidase expression in Arabidopsis causes a lesion-mimic phenotype that induces systemic acquired resistance. Plant J. 17:667-678.

Nandi, A., Kachroo, P., Fukushige, H., Hilderbrand, D. F., Klessig, D. F., and Shah, J. 2003. Ethylene and jasmonic acid signaling affect the NPR1-independent expression of defense genes without impacting resistance to Pseudomonas syringae and Peronospora parasitica in the Arabidopsis ss 1 mutant. Mol. Plant-Microbe Interact. 7:588-599.

Niki, T., Mitsuhara, I., Seo, S., Ohtsubo, N., and Ohashi, Y. 1998. Antagonistic effect of salicylic acid and jasmonic acid on the expression of pathogenesis-related (PR) protein genes in wounded tobacco leaves. Plant Cell Physiol. 39:500-507.

Nishizawa, Y., Nishio, Z., Nakazono, K., Soma, M., Nakajima, E., Ugaki, M., and Hibi, T. 1999. Enhanced resistance to blast (Magnaporthe grisea) in transgenic rice by constitutive expression of rice chitinase. Theor. Appl. Genet. 99:383-390.

Nishizawa, Y., Saruta, M., Nakazono, K., Nishio, Z., Soma, M., Yoshida, T., Nakajima, E., and Hibi, T. 2003. Characterization of transgenic rice plants over-expressing the stress-inducible $\beta$-glucanase gene, Gns1. Plant Mol. Biol. 51:143-152.

Pontier, D., Mittler R., and Lam, E. 2002. Mechanism of cell death and disease resistance induction by transgenic expression of bacterioopsin. Plant J. 30:499-509.

Rao, M., Lee, H., Creelman, R., Mullet, J., and Davis, K. 2000. Jasmonic acid signaling modulates ozone-induced hypersensitive cell death. Plant Cell 12:1633-1646.

Raskin, I. 1992. Role of salicylic acid in plants. Annu. Rev. Plant Physiol. Plant Mol. Biol. 43:439-463.

Rizhsky, L., and Mittler, R. 2001. Inducible expression of bacterioopsin in transgenic tobacco and tomato plants. Plant Mol. Biol. 46:313-323.

Ryals, J. A., Neuenschwander, U. H., Willitis, M. G., Molina, A., Steiner,
H. Y., and Hunt M. D. 1996. Systemic acquired resistance. Plant Cell 8:1809-1819.

Schaffrath, U., Freydl, E., and Dudler, R. 1997. Evidence for different signaling pathways activated by inducers for acquired resistance in wheat. Mol. Plant-Microbe Interact. 10:779-783.

Sehgal, O. P., Rieger, R., and Mohamed, F. 1991. Induction of bean PR 4d-type protein in divergent plant species after infection with tobacco ring spot virus and its relationship with tobacco PR 5. Phytopathology 81:215-219.

Silverman, P., Seskar, M., Kanter, D., Schweizer, P., Metraux, J.-P., and Raskin, I. 1995. Salicylic acid in rice. Plant Physiol. 108:633-639.

Swegle, M., Kramer, J., and Muthukrishnan, S. 1992. Properties of barley seed chitinase and release of embryo-associated isoforms during early stages of inhibition. Plant Physiol.99:1009-1014.

Takahashi, H., Chen, Z., Du, H., Liu, Y, and Klessig, D. F. 1997. Development of necrosis and activation of disease resistance in transgenic tobacco plants with severely reduced catalase levels. Plant J. 11:9931005.

Thordal-Christensen, H., Zhang, Z., Wei, Y., and Collinge, D. B. 1997. Subcellular localization of $\mathrm{H}_{2} \mathrm{O}_{2}$ in plants, $\mathrm{H}_{2} \mathrm{O}_{2}$ accumulation in papillae and hypersensitive response during barley-powdery mildew interaction. Plant J. 11:1187-1194.

van der Straeten, D., Chaerle, L., Sharkov, G., Lambers, H., and van Montagu, M. 1995. Salicylic acid enhances the activity of the alternative pathway of respiration in tobacco leaves and induces thermogenicity. Planta 196:412-419.

Walbot, V., Hoisington, D. A., and Neuffer, M. G. 1983. Disease lesion mimics in maize. Pages 431-442 in: Genetic Engineering of Plants. T. Kosuge and C. Meredith, eds. Plenum, New York.

Ward, E. R., Uknes, S. J., Williams, S. C., Dincher, S. S., Wiederhold, D L., Alexander, D. C., Ahl-Goy, P., Metraux, J.-P., Ryals, J. A. 1991. Coordinate gene activity in response to agents that induce systemic acquired resistance. Plant Cell 3:1085-1094.

White R. F. 1979. Acetylsalicylic acid (aspirin) induces resistance to tobacco mosaic virus in tobacco. Virology 99:410-412.

Wolter, M., Hollricher, K., Salamini, F., and Schulze-Lefert, P. 1993. The mlo resistance alleles to powdery mildew infection in barley trigger a developmentally controlled defence mimic phenotype. Mol. Gen Genet. 239:122-128.

Woodward, J. R., and Fincher, G. B. 1982. Purification and chemical properties of two 1,$3 ; 1.4-\beta$-glucan endohydrolases from germinating barley. Eur. J. Biochem. 121:663-669.

Yang, Y., Shah, J., and Klessig, D. F. 1997. Signal perception and transduction in plant defense responses. Genet. Dev. 11:1621-1639.

Zhu, Q., Maher, E. A., Maced, M., Dixon, R. A., and Lamb, C. 1994. Enhanced protection against fungal attack by constitutive co-expression of chitinase and glucanase genes in transgenic tobacco. Bio/Technology 12:807-812. 